\title{
LeItURA: INFERÊnCIAS NA ObRA de Fernando SABino
}

Ricardo Santos David

DOI 10.11606/issn.1981-7169.crioula.2017.125489

RESUMO: Análise de inferências em textos com o objetivo de demonstrar que todo sentido, mesmo o literal, inclui informações implícitas em diferentes graus de explicitude. $O$ ato de compreensão desses enunciados envolve vários processos inferenciais, o que significa dizer que o leitor crítico deve estar atento não só às questões de ordem lógica como também às questões discursivas e ou retórico-argumentativas que ocorrem nos diversos gêneros de textos e que são fundamentais para a construção dos sentidos.

ABSTRACT: Analysis of inferences in texts, with the objective of demonstrating that the sense, even the literal one, is implicit in the discourse in different degrees. The comprehension of these texts indicates inferencial operations, what it means that the reader must attent to the logical questions and to the discursive or argumentative ones in different kinds of texts and that they are important to the construction of the sense of a text.

PALAVRAS-CHAVE: inferência; operações implícitas; interpretação de texto.

KEYWORDS: Inferences; implicit operations; text interpretation. 
REVISTA CRIOULA N ${ }^{\circ} 19-1^{\circ}$ SEMESTRE/2017

\section{INTRODUÇÃO}

nferência é a conclusão de um processo cognitivo por meio do qual uma assertiva é feita a respeito de algo desconhecido, tendo como base uma observação. No dia a dia, é possível, por exemplo, inferir a riqueza de uma pessoa observando seu modo de vida, a gravidade de um acidente de trânsito pelo estado dos veículos envolvidos e o sabor de um alimento pelo seu aroma. A inferência revela-se como uma conclusão de um raciocínio, uma expectativa, fundamentada em um indício, uma circunstância ou uma pista. Assim, fundamentando-se em uma observação ou em uma proposição, são estabelecidas algumas relações (evidentes ou prováveis) e chega-se a uma conclusão decorrente do que se captou ou julgou.

A concepção de que a inferência representa uma ligação entre duas ideias é assumida desde a Antiguidade. Esse termo vem do latim medieval "inferre" e designa o fato de duas proposições se interligarem, sendo que, nessa conexão, a antecedente implica a consequente. Inferir é uma atividade associativa que pressupõe uma ordem, uma sequência entre as proposições.

Numa leitura do resultado da compreensão depende da qualidade das inferências geradas. Os textos possuem informações explícitas e implícitas; existem sempre lacunas a serem preenchidas. O leitor infere ao associar as informações explícitas aos seus conhecimentos prévios e, a partir daí, gerar sentido para o que está informado, de algum modo, pelo texto ou por meio dele. A informação fornecida direta ou indi- 
retamente é uma pista que ativa uma operação de construção de sentido. Portanto, ao contrário do que muitos acreditam, a inferência não está no texto, mas na leitura, e vai sendo construída à medida que leitores vão interagindo com a escrita. Falar em leitura remete à questão da produção de sentidos constituídos no contexto de interação recíproca entre autor e leitor via texto, os quais se expressam diferentemente, de acordo com a subjetividade do leitor: seus conhecimentos, suas experiências e seus valores. Nesse caso, pode-se dizer que o texto constrói-se a cada leitura, não trazendo em si um sentido preestabelecido pelo seu autor, mas uma demarcação para os sentidos possíveis.

Na produção de sentidos, o leitor desempenha um papel ativo, sendo as inferências um processo cognitivo relevante para esse tipo de atividade. Isto ocorre porque elas possibilitam a construção de novos conhecimentos a partir de dados previamente existentes na memória do interlocutor, que são ativados e relacionados às informações veiculadas pelo texto. Esse processo favorece a mudança e a transformação do leitor, que, por sua vez, modifica o texto.

O presente artigo pretende fazer uma reflexão teórica sobre o papel da leitura. O que será, não obstante, que garante a organização desses sentidos por parte do leitor? Que processo cognitivo permite ao leitor atribuir coerência ao texto, imprimindo nele a sua interpretação? O processo inferencial! É este processo que vai permitir e garantir a organização dos sentidos elaborados pelo indivíduo na sua relação com o texto. É a partir dele que o estabelecimento das relações entre as partes do texto e entre estas e o contexto torna-se possível, fazen- 
do dele uma unidade aberta de sentido. Acredita-se que, além de favorecer a organização das relações de significado dentro do texto, o processo inferencial permite destacar a malha ou teia de significados que o leitor é capaz de estabelecer dentro do horizonte de possibilidades que é o texto.

\section{Conceito de InfERÊnCIA}

Em 1939, Hayakawa propunha a seguinte definição de inferência: "uma asserção sobre o desconhecido, feita na base do conhecimento". McLeod (1977:6) avança e especifica a noção de Hayakawa, descrevendo inferência como "uma informação cognitivamente gerada com base em informações explícitas, linguísticas ou não linguísticas, desde que em um contexto de discurso escrito contínuo, e que não tenha sido previamente estabelecido".

Bridge (1977:11) define inferência "como uma informação semântica não explicitamente estabelecida no texto, mas gerada pelo leitor durante o processo inferencial de especificação de proposições". Frederiksen (1977:7) combina muitos dos elementos de cada uma dessas definições.

Para ele,

Inferência ocorre sempre que uma pessoa opera uma informação semântica, isto é, conceitos, estruturas proposicionais ou componentes de proposições, para gerar uma nova informação semântica, isto é, novos conceitos de estrutura proposicionais. Qualquer conhecimento semântico que é gerado desse modo é inferido. 
Em todos esses conceitos, pode-se observar um ponto em comum: as inferências ocorrem na mente do leitor. Como afirma Flood (1981:55): "o texto existe, o leitor infere".

Uma primeira constatação é a que a inferência não está no texto. É uma operação que os leitores desenvolvem enquanto estão lendo o texto ou após terem completado a sua leitura. O texto serve como um estímulo para geração de inferências.

Para ilustrar, Rickheit, Shnotz \& Strohner (1985) apresentam a seguinte fórmula:

Inferência $=$ A B

C

em que A é a informação antiga, B é a informação nova, C o contexto e a seta é o processo de geração de inferência. O processo é distribuído em três partes:

- a representação psicológica das informações A e B;

- a operação de inferência de B extraída de A;

- a noção de contexto $C$ e seu efeito sobre a inferência.

A inferência anterior ( $A$ ) apresenta um conteúdo semântico já conhecido ou que está sendo conhecido pelo leitor, enquanto a informação nova (B) é extraída a partir de $(A)$ e sob a influência de um contexto (C). Dessa forma, A e B são representações psicológicas individuais, mas mantêm relações passíveis de identificação.

Morrow (1990) entende inferência como o modo pelo qual os leitores, para compreender uma narrativa, ativam e usam 
informações nela implícitas e não mencionadas. Mckoon e Ratcliff (1992) definem inferência como qualquer informação não explícita em um texto.

Dada à abrangência dessas definições, optou-se pela elaboração de um conceito que sintetiza aspectos relevantes apontados pelos teóricos e necessários para que sua manifestação seja identificada. O conceito de inferência aqui concebido é: "Inferência é um processo cognitivo que gera uma informação semântica nova, a partir de uma informação semântica anterior, em um determinado contexto".

Inferência é, pois, uma operação mental em que o leitor constrói novas proposições a partir de outras já dadas. Não ocorre apenas quando o leitor estabelece elos lexicais ou organiza redes conceituais no interior do texto, mas também quando o leitor busca, extratexto, informações e conhecimentos adquiridos pela experiência de vida, com os quais preenche os "vazios" textuais. O leitor traz para o texto um universo individual que interfere na sua leitura, uma vez que extrai inferências determinadas por contextos psicológico, social, cultural, situacional, dentre outros.

Várias perguntas podem ser levantas a respeito do processo de inferir: como as inferências são geradas? Qual a atuação da memória durante o processo de inferir? Como as inferências são mentalmente representadas? Quando uma inferência é produzida? Quais os tipos de inferências existentes? Que influências contextuais agem sobre o processo? Em que grau as inferências dependem do contexto? 


\section{FUNDAMENTAÇÃO TEÓRICA: A GERAÇÃO DE INFERÊNCIAS}

Uma infinidade de pesquisas sobre a geração de inferências tem-se desenvolvido sob as perspectivas da Psicologia, da Semântica, da Inteligência Artificial, da Linguística e da Cognição.

No campo da Psicologia Desenvolvimentista, tem-se focalizado as relações entre a inferência e os aspectos temporais, espaciais, causais e lógicos. No campo da Semântica, o estudo da geração de inferências tem sido um assunto central. Jackendoff (1975:29), por exemplo, propôs um sistema constituído de princípios organizacionais disponíveis ao usuário da língua, relacionados à sua habilidade de abstração "ao compreender novos modos de interpretação e ao ser capaz de generalizar regras de inferência a um sistema de relações". Há estudos sobre inferência dentro dos limites da sentença (Clark, 1975) e sobre inferência conversacional em uma Teoria da Estrutura do Ato da Fala (Grice, 1971).

Pesquisadores da Inteligência Artificial preocupam-se em construir modelos de processos envolvidos na compreensão, conectados ao discurso e à geração de Inferências. Schank \& Abelson (1975), por exemplo, criaram a possibilidade de reconhecimento inferencial através de perguntas e respostas. Teóricos da Inteligência Artificial sustentam que a geração de inferências é um fenômeno que ocorre simultânea e sequencialmente durante o processo inferencial dos textos. Vários modelos de processo inferencial têm sido por eles testados.

Linguistas cognitivos tomam uma dentre duas posições quanto à compreensão de sentenças e o processo de inferên- 
cia: ou sugerem que o ouvinte extrai da estrutura profunda relações do input da sentença, que se armazenam na memória por meio de traços binários, ou sugerem que o ouvinte constrói ativamente uma representação interna para as sentenças. Os que tomam a primeira posição são chamados de Teóricos da Linguística Objeto; os que adotam a segunda postura são chamados Teóricos da Assimilação.

Entre os primeiros estudiosos que desenvolveram pesquisas sobre a geração de inferências destacam-se Bartett (1932), Kintsch (1974) e Bridge (1977) Bartlett explicou a inferência do discurso em uma Teoria Construtiva de Esquema. Recentemente, noções similares expressam que esquemas operam nos níveis da palavra/conceito, da proposição, do trecho textual, e que os leitores constroem significado a partir do texto.

\section{AnÁlise infEREnCIAL}

Partindo-se da hipótese de que o contexto sociocultural do indivíduo atuaria como um fator condicionante da variedade de interpretações de texto, foi aplicado o teste "pausa protocolada previamente marcada no texto". Submeteram-se ao teste alunos representativos da classe A e B.

O texto "Piscina", de Fernando Sabino, foi dividido em dez pausas. Após cada pausa, os alunos responderam, oralmente ou por escrito, às perguntas feitas pelo pesquisador.

A cada intervalo de texto, segue-se um conjunto de perguntas. Recapitulando, os três tipos de perguntas são: as objetivas, as inferenciais e as avaliativas. A entrevista foi apenas 
parcialmente estruturada, pois, à medida que o aluno inferia, perguntas não previstas eram elaboradas. Uma resposta inferencial, muitas vezes, exige uma nova pergunta além das previamente estabelecidas. Por isso, a série de perguntas sobre o texto serviu apenas de roteiro ao pesquisador.

Veja-se a seguir a estrutura do teste aplicado.

\section{TESTE}

$1^{\circ}$ parte:

O título: "Piscina"

Pergunta objetiva:

- O que é uma piscina?

Perguntas inferenciais:

- Você já nadou em uma piscina? Onde?

- Você é sócio de algum clube? Você tem piscina em sua casa?

- Onde você já viu uma piscina?

- Sobre o que o texto vai falar? Invente uma possível história para esse título.

Pergunta avaliativa:

- Você gosta de nadar? 


\section{$2^{\circ}$ Parte:}

O autor apresenta as circunstâncias:

"Era uma esplêndida residência, na Lagoa Rodrigo de Freitas, cercada de jardins e tendo ao lado uma bela piscina".

Perguntas objetivas:

- Onde se situava a residência?

- Como era a residência?

- E o que havia do lado de fora da residência?

Perguntas inferenciais:

- Onde fica a Lagoa Rodrigo de Freitas?

- Como você imagina que seja a região onde está a residência?

- Como é uma esplêndida residência? Como são as pessoas que nela moram?

- Como é vizinhança?

- Invente uma continuação para história.

\section{$3^{\circ}$ Parte:}

"Pena que a favela, com seus barracos grotescos se alastrando pela encosta do morro, comprometessem tanto a paisagem".

Perguntas objetivas:

- O que havia perto da residência? 
- O que, na opinião do autor, comprometia a paisagem?

Perguntas inferenciais:

- Como são "barracos grotescos"? Por que eles "se alastravam" pela encosta do morro?

- Por que é "pena" existir uma favela por perto?

- Descreva a favela. Como você acha que devem ser as pessoas que moram na favela?

Perguntas avaliativas:

- Você concorda que uma favela compromete a paisagem? Por quê?

\section{$4^{\circ}$ Parte:}

\section{Exposição de circunstâncias}

Diariamente desfilavam diante do portão aquelas mulheres silenciosas e magras, lata d'água na cabeça. De vez em quando surgia sobre a grade a carinha de uma criança, olhos grandes e atentos, espionando o jardim. Outras vezes eram as próprias mulheres que se detinham e ficavam olhando.

Perguntas objetivas:

- O que acontecia todos os dias?

- Quem são "aquelas mulheres"? Como elas eram? O que tinham sobre a cabeça?

- Quem dava uma espiada no jardim? Quem se detinha e ficava olhando. 
Perguntas inferenciais:

- Por que as mulheres e as crianças ficavam olhando em direção a casa?

- O que elas pensavam?

- Crie uma continuação para história.

\section{Parte:}

"Naquela manhã de sábado ele tomava seu gim tônico no terraço, e a mulher um banho de sol, estirada de maiô à beira da piscina, quando perceberam que alguém os observava pelo portão entreaberto".

Pergunta objetiva:

- O que aconteceu naquela manhã de sábado?

Perguntas inferenciais:

- Naquela manhã de sábado quem tomava gim tônico no terraço?

- Quem era ele?

- Como estava a mulher?

- Quem os observava pelo portão entreaberto? Quem você acha que era? O que queria? Para que estava ali?

\section{$6^{\circ}$ Parte:}

Complicação = conflito entre a protagonista e a antagonista. "Era um ser encardido, cujos molambos em forma de saia não bastavam para defini-la como mulher. Segurava uma lata 
na mão, e estava parada, à espreita, silenciosa como um bicho. Por um instante as duas mulheres se olharam separadas pela piscina".

Perguntas objetivas:

- Quem os observava pelo portão?

- Como ela estava vestida?

- O que ela parecia?

Perguntas inferenciais:

- As duas mulheres se olharam separadas pela piscina. Evidencie as diferenças entre a dona da casa e a mulher da favela quanto:

à habitação ao vestuário

à postura física

à ocupação na manhã de sábado

- O que vai acontecer agora?

\section{$7^{\circ}$ Parte:}

Início do clímax

"De súbito pareceu à dona da casa que a estranha criatura se esgueirava, portão adentro, sem tirar os olhos dela. Ergueu-se um pouco, apoiando-se no cotovelo, e viu com terror que ela se aproximava lentamente":

Perguntas objetivas:

- A quem o autor chama de "estranha criatura"? 
- O que a mulher da favela fez?

- Qual a reação da dona de casa?

Perguntas inferenciais:

- Por que a mulher dona da casa sentiu terror com a aproximação da outra mulher?

- O que a dona da casa pensou?

- Para que a mulher da favela entrou na residência? O que de fato ela queria entrando pelo portão?

\section{$8^{\circ}$ Parte:}

Ponto de maior tensão na narrativa

"já transpusera o gramado, atingia a piscina, agachava-se junto à borda de azulejos, sempre a olhá-la, em desafio, e agora colhia água com lata. Depois, sem uma palavra, iniciou uma cautelosa retirada, meio de lado, equilibrando a lata na cabeça e em pouco sumia-se pelo portão".

Perguntas objetivas:

- Para que a mulher da favela entrou na residência?

- Como ela saiu da residência?

Perguntas inferenciais:

- Por que a mulher da favela decidiu encher a lata na piscina, em vez de buscar água no local de costume?

- De que forma a invasora colheu a água da piscina?

"Sempre a olhá-la em desafio".

- Por que o olhar em desafio? 
- Desafiar significa propor combate. Qual era o combate? O que se pretendia defender? Qual é o objeto do combate?

- O que vai acontecer agora? O que os donos da casa vão fazer?

Pergunta avaliativa:

- Você acha que a mulher da favela fez bem ou mal ao tirar água da piscina? Por quê?

\section{$9^{\circ}$ Parte:}

Início do desfecho

"Lá no terraço o marido, fascinado, assistiu a toda a cena. Não durou mais de um ou dois minutos, mas lhe pareceu sinistra como os instantes tensos de silêncio e de paz que antecedem um combate".

Perguntas objetivas:

- Quem assistiu à cena?

- Quanto tempo durou a cena?

- O que pareceu ao marido?

Perguntas inferenciais:

- Quem eram os combatentes?

- Qual era o objeto do combate?

- Que combate era esse?

- O que significa fascinado neste contexto?

- O que vai acontecer agora? 


\section{$10^{\circ}$ Parte:}

Desfecho e solução do conflito

"Não teve dúvida: na semana seguinte vendeu a casa".

Pergunta objetiva:

- O que o dono da casa fez?

Perguntas inferenciais:

- Por que o dono vendeu a casa? Qual foi a causa de o marido ter vendido a casa?

- Se você fosse o dono da casa e esse fato tivesse acontecido com você, você venderia a casa? Por quê?

- Qual seria sua reação?

- Que providências você tomaria?

Pergunta avaliativa:

- Você acha que ele fez bem ou mal? Justifique a sua resposta.

O mecanismo literário principal do texto, ou seja, o "não-dito" (ECO, p. 67) no qual o leitor pode atuar para completar o sentido do texto, é a oposição entre a piscina e a lata, entre o poder de possuir uma piscina, utilizando a água para lazer, e a falta de poder que leva a utilização de uma lata como reservatório para a água necessária à sobrevivência. A piscina separa, divide as mulheres: "Por um instante, as duas mulheres se olharam, separadas pela piscina". Muito mais do que separadas fisicamente pela piscina, as duas mulheres viviam duas realidades distintas, quase opostas, e a piscina é sím- 
bolo desta distância. A piscina aparece como um degrau que distancia as mulheres. Outra evidência da distinção social é a forma como as mulheres são descritas. De um lado, "a mulher tomava um banho de sol, sentada de maio à beira da piscina", e de outro "um ser encardido cujos trapos em forma de saia não bastavam para defini-la como mulher". A oposição entre "mulher" e "ser" abre para o leitor um espaço no qual ele pode atuar com sua visão de mundo, trazendo a tona um conjunto de significados capazes de preencher as lacunas do texto, uma vez que todo texto é uma "estratégia de comunicação" (ECO, p. 181). De um lado, há uma mulher, e, de outro, há um "ser". "Mulher" traz consigo significados que vão desde o sexo biologicamente definido até imposições sociais, como a busca pela beleza física representada pelo banho de sol e pelo maiô. Já o "ser" é biologicamente vivo, está em busca de sobrevivência, por isso precisa da água, mas está distante de mecanismos sociais que a definam como mulher, como seriam as roupas, se fosse suficientes para tanto.

\section{Considerações finaIS}

O texto "Piscina", de Fernando Sabino, pode ser trabaIhado no Ensino fundamental e médio com o objetivo de levar o aluno a refletir sobre diversos aspectos, tais como: desigualdade social, nutrição e saúde. É interessante destacar que a água da piscina recolhida pela mulher da favela é utilizada como um nutriente, ou seja, algo necessário para a saúde do ser humano. Em clara oposição, a água da piscina é utilizada apenas para lazer pelos donos do casarão, em outras pala- 
vras, é um elemento de luxo. A questão da desigualdade social pode ser trazida à tona, tanto pelo valor crítico que representa quanto pela sua capacidade humanizadora.

A discussão sobre os problemas sociais constitui um ponto importante do trabalho com literatura em sala de aulas. Ela também permite fazer perceber a multiplicidade de modos de vida existentes na sociedade brasileira, questionar se esta multiplicidade é positiva ou não, até que ponto trata-se apenas de multiplicidade e a partir de que ponto se torna uma questão de desigualdade social. Assim, a literatura pode colocar os alunos em contato com o outro em sua sociedade, sem que este contato seja negativo ou prejudicial.

Outro ponto importante é sobre questões ambientais. Uma piscina utiliza uma grande quantidade de água, desse modo não seria um desperdício? A mídia sempre está em alerta para a economia do consumo de água já que ela pode acabar daqui alguns anos, mas as piscinas continuam sendo apresentadas como símbolo de poder. Também pode ser explorada a questão de segurança, pois a mulher com a lata na mão entrou tranquilamente no quintal alheio, recolheu a água e foi embora. Ela teve um fácil acesso. Assim, pode-se questionar o quanto os poderes públicos investem ou deixam de investir em segurança, e também se os investimentos que são feitos vão para o caminho certo, pois não apenas falta segurança na casa de classe alta, mas falta cidadania para a mulher com a lata. Pode-se trabalhar para que o estudante desenvolva sua consciência para tomada de decisões enquanto cidadão ativo na resolução de questões relacionadas a medidas econômicas. Podem-se abordar questões como: 
Uma piscina é uma obra que tem um custo alto para construir e manter, será que vale a pena tal investimento? Qual a importância e a real motivação para se ter uma?

O texto "Piscina", sem dúvida proporcionou certo incômodo íntimo aos leitores. Os leitores, ao interpretá-lo, deixaram transparecer as suas posturas ideológicas determinadas pela classe social e que cada um pertencia a representava.

As perguntas objetivas, de conhecimento informado pelo texto, foram elaboradas com o objetivo de verificar a compreensão do leitor sobre aquilo que está no texto.

As perguntas inferenciais, baseadas nos conhecimentos experienciais, nas crenças, ideologias e axiologias individuais, foram formuladas visando verificar as expectativas e as ideias do leitor referentes às ideias expressas no texto e ao conhecimento de mundo relacionado com a camada sociocultural em que o aluno está inserido.

As perguntas avaliativas envolvem julgamentos pessoais de informações fornecidas pelo texto. Através desse tipo de questão, verificaram-se as reações do leitor diante das ideias apresentadas, confrontando o seu ponto de vista com o ponto de vista exposto no texto, argumentando a favor de sua opinião e aprofundando a sua reflexão. Todas as palavras que com maestria foram selecionadas pelo autor do texto servem para mostrar o contraste entre a riqueza de alguns e a miséria de outros. A mulher da favela é associada a um bicho, a um ser indefinido, sem identidade. O narrador se refere a ela como um "ser encardido", "silenciosa como um bicho", "estranha criatura”. À marginalização social corresponde a desumanização da personagem. Enfim, o título "Piscina" é o grande 
divisor de águas. Para a mulher da mansão a piscina significava o ócio, o luxo, a ostentação, para a outra, a sobrevivência, um bem vital. A piscina serve como o símbolo da desigualdade social, e é disto que trata o texto - o sentido mais global.

Fica claro, assim, que o léxico cumpre grande importância na construção de sentidos. Quanto maior for o conhecimento prévio do léxico melhor será a construção e reconstrução de sentidos do texto.

Vimos de forma geral como o uso de estratégias concorre para a compreensão da compreensão leitora que em consonância ao que postula Castro \& Dionísio (2003) os textos devem ser lidos autonomamente e não como estes vêm sidos normalmente praticados nos exercícios de compreensão leitora que com seus enunciados interrogativos, declarativos e imperativos apontam para uma compreensão predeterminada pelo autor do livro didático atribuindo aos leitores papéis interpretativos determinados. A partir das repostas obtidas, foram analisadas: as inferências que envolvem compreensão textual, as inferências que envolvem percepção afetiva e avaliação como consequência de julgamentos sociais. O dever da escola e dos professores em geral é fazer com que o aluno aprenda o que não sabe. A crônica "Piscina", de Fernando Sabino, faz uma crítica à desigualdade social, assunto polêmico que se mantém atual há muitas décadas.

Certo dia, os moradores de uma casa luxuosa localizada em um morro próximo a uma favela, observaram que os seus vizinhos moradores desta favela, adentravam e roubaram alguma coisa: a água da piscina! Fato inusitado? Não para o autor da crônica. 
Com palavras simples e habilidade na escrita, Fernando Sabino perpassa por várias esferas do problema da desigualdade social. Moradores que convivem em uma mesma cidade, vizinhos, vivendo situações sociais tão diferentes. Aborda desde os problemas de saneamento básico, passando pela cultura da ostentação, educação, chegando ao medo da violência e a falta de segurança. Ler o mundo ele já sabe. $\mathrm{O}$ que precisa aprender ler é a palavra, não a decodificação desta isoladamente, mas parafraseando Bakhtin (1997) a palavra que constitui o produto da interação do locutor e do ouvinte. Um dos objetivos deste artigo foi discutir a importância da compreensão leitora e que para atingir tal habilidade, o professor pode lançar mão das estratégias de leitura que de uso sistemático incorporarão ao ato de ler dos aprendizes e estes paulatinamente transformar-se-ão em leitores proficientes. Um dos fatores que afetam a sociedade brasileira é a questão da Desigualdade Social, onde os ricos ficam cada vez mais ricos e os pobres vão entrando ainda mais na miséria. $E$ é isso que o autor procura passar na sua crônica, a partir do momento que ele descreve a bela e luxuosa casa de um casal e da vida pobre das pessoas que invadem a casa para roubarem à água da piscina. $\mathrm{O}$ autor revela os contrastes sociais que já estamos acostumados a vivenciar, com notícias na televisão e jornais. Nessa crônica ele atinge de certa forma, os políticos, que estão no poder e não fazem nada para melhorar a vida de quem os elegeu. 


\section{REFERÊNCIAS BIBLIOGRÁFICAS}

BAKHTIN, Mikhail (1997). Marxismo e filosofia da linguagem. $8^{a}$ ed. São Paulo: Hucitec.

BRIDGE, C. The text based inferences generated by children in processing writing discourse. University of Arizona, 1977.

ECO, Umberto. Leitura do texto literário: Lector in fabula. Lisboa: Presença, 1979.

CASTRO, Rui Vieira de; DIONÍSIO, Maria de Lourdes. "A produção de sentido(s) na leitura escolar: dispositivos pedagógicos e estratégias discursivas no 'trabalho interpretativo'”. In: FELTES, Heloísa Pedroso de Moraes. Produção de sentido: estudos transdisciplinares. São Paulo: Annablume; Porto Alegre: Nova Prova; Caxias do Sul: Educs, 2003.

DELL'ISOLA, Regina Lúcia Péret. Leitura: Inferências e contexto sociocultural. Belo Horizonte: Formato Editorial, 2001.

FREDERIKSEN, J. R. "Semantic processing units in understanding text". In: FREEDLE, O. (org). Discourse production and comprehension. Ablex: Northwood, 1977.

HAYAKAWA, S. J. "A linguagem dos comunicados". In: HAYAKAWA, S. J. A linguagem no pensamento e na ação. São Paulo: Pioneira, 1963. Cap.3, p.29-42. 
MCLEOD, J. Inference and cognitive synthesis. Universidade de Alberta. Dissertação de doutorado, 1977.

RICKHEIT, Gert; SCHNOTZ, Wolfgang; STROHNER, Hans. "The concept of inference in discourse comprehension". In: RICKHEIT, Gert; STROHNER, Hans (Eds.). Inferences in text processing. Amsterdam: North Holland, 1985. p. 3-47.

SABINO, Fernando. "Piscina", In: A mulher do vizinho. Rio: Nova Fronteira, 1976.

\section{Anexo}

\section{Piscina}

Fernando Sabino

Era uma esplêndida residência, na Lagoa Rodrigo de Freitas, cercada de jardins e tendo ao lado uma bela piscina. Pena que a favela, com seus barracos grotescos se alastrando pela encosta do morro, comprometessem tanto a paisagem.

Diariamente desfilavam diante do portão aquelas mulheres silenciosas e magras, lata d'água na cabeça. De vez em quando, surgia sobre a grade a carinha de uma criança, olhos grandes e atentos, espiando o jardim. Outras vezes eram as próprias mulheres que se detinham e ficavam olhando. 
Naquela manhã de sábado, ele tomava seu gim-tônica no terraço, e a mulher um banho de sol, estirada de maiô à beira da piscina, quando perceberam que alguém os observava pelo portão entreaberto.

Era um ser encardido, cujos molambos em forma de saia não bastavam para defini-la como mulher. Segurava uma lata na mão, e estava parada, à espreita, silenciosa como um bicho. Por um instante as duas se olharam, separadas pela piscina.

De súbito, pareceu à dona da casa que a estranha criatura se esgueirava, portão adentro, sem tirar dela os olhos. Ergueu-se um pouco, apoiando-se no cotovelo, e viu com terror que ela se aproximava lentamente: já transpusera o gramado, atingia a piscina, agachava-se junto à borda de azulejos, sempre a olhá-la em desafio, e agora colhia água com a lata. Depois, sem uma palavra, iniciou uma cautelosa retirada, meio de lado, equilibrando a lata na cabeça - e em pouco tempo sumia-se pelo portão.

Lá no terraço, o marido, fascinado, assistiu a toda à cena. Não durou mais de um ou dois minutos, mas lhe pareceu sinistra como os instantes tensos de silêncio e de paz que antecedem um combate. Não teve dúvida: na semana seguinte vendeu a casa.

Submissão: 2017-02-09

Aceite: 2017-03-16 